AAAJ
31,6

1830

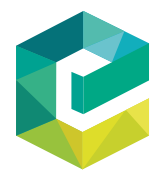

Accounting, Auditing \& Accountability Journal Vol. 31 No. 6, 2018 pp. $1830-1830$ (C) Emerald Publishing Limited 0951-3574

DOI 10.1108/AAAJ-08-2018-017

\section{How to deal with rejections: use of the middle finger}

Much has been written about how academics might respond to manuscripts rejected from journals. It is something all researchers have and will need to face in the future. Like many formidable challenges, how we react to such decisions is likely to be instrumental in determining our future success.

Here is a suggested response that senior, mid-career, as well as early career researchers might consider when receiving the "Decision on Manuscript" e-mail...

Dear Editor.

I regret to inform you that my co-author and I cannot accept your letter of rejection of our paper. It does not make a sufficient contribution to our research agenda at this time. Although your letter is well-written, addresses an important issue (our future career progression), and one we certainly enjoyed reading, at this time of writing, we have a large number of particularly high quality rejections making the choice of which rejection letter to accept somewhat difficult, as I am sure you can understand.

Senior colleagues of mine who read your letter gave reviews that concurred with my own negative impression. One (Dr McEnroe) said, "I don't believe he wrote this letter to you - he cannot be serious". Another (Professor Shyster) wrote, "You have yourself to blame, this would never have happened if you cited their journal more in your references". In the interests of fairness, however, I have taken counsel from my co-author who bears some responsibility for the unmitigated rubbish contained in our original submission and our three pitiful attempts at revision. His/her view is that the theoretical basis upon which your letter is founded requires considerable work, the letter itself is poorly motivated, and the on the basis of your feedback is difficult to infer the results beyond the sample (us).

Having said this, we do appreciate your dismissal of our paper - particularly after a review process which consumed over 18 months of valuable research time, three revisions and contrary reviews by referees who are clearly intellectual giants, the shoulders upon which both my co-author and I would definitely like to stand. Your referees were particularly adept at demonstrating how clever they are, and their constructive comments were entirely subjective and opinionated. Please convey our thanks to them for reinforcing the fact that after all, rejection is part of a learning process, and what does not kill you makes you stronger. This is something we consider might be worthwhile for you to reflect on in this particular instance.

This decision should in no way be read as a judgment of quality or interest in your work (although it obviously is), and I encourage future rejection letters from you on subsequent submissions to your journal, because I am sure it will increase your impact, ranking or citation metrics in some way. I am sorry that the outcome was not more favourable, and wish you all the best with your future rejections.

Basil Tucker School of Commerce, University of South Australia, Adelaide, Australia 